months after vaccination. During the observation period, none of the patients had an exacerbation of the disease, reliably associated with the vaccination. There was no recurrence of thrombosis, both in patients receiving anticoagulant therapy and without it. No new autoimmune phenomena, both clinical and laboratory, were identified. The dynamics of the production of anti-streptococcal antibodies during the year was followed in 16 patients. One year after vaccination, $31 \%$ of patients showed a significant (more than 2-fold compared to the initial) increase in the concentration of antibodies to polysaccharides of the cell wall of S. pneumoniae ("responders"), $69 \%$ of patients were "non-responders" to the vaccine. At the same time, all 5 patients with PAPS were "non-responders", and $45.5 \%$ "respondents" with sAPS.

Conclusion: Preliminary results show that patients with APS tolerate PPV-23 vaccination well. In the next post-vaccination period, exacerbations of the disease, thrombosis were not recorded. Attention is drawn to the large number of "non-responders" in PAPS, however, to obtain statistically reliable results, it is necessary to continue the study and recruit more patients.

Disclosure of Interests: None declared

DOI: 10.1136/annrheumdis-2021-eular.1447

\section{AB0311 INCREASED LEVELS OF SERUM WISTERIA FLORIBUNDA AGGLUTININPOSITIVE MAC-2 BINDING PROTEIN IN RHEUMATIC DISEASES INCLUDING SLE}

T. Yoshikawa ${ }^{1}$, K. Azuma ${ }^{1}$, T. Furukawa ${ }^{1}$, M. Tamura ${ }^{1}$, T. Hashimoto ${ }^{1}$, M. Morimoto ${ }^{1}$, N. Azuma ${ }^{1}$, K. Matsui ${ }^{1}{ }^{1}$ Hyogo College of Medicine College Hospital, Division of Allergology and Rheumatology, Department of Internal Medicine, Nishinomiya-City, Japan

Background: Mac-2 binding protein is a cell-adhesive glycoprotein of the extracellular

matrix secreted as a ligand of galectin-3 (Mac-2). Recently, a Wisteria floribunda agglutinin positive-M2BP (M2BP) assay developed using a lectin-antibody sandwich

immunoassay has shown promise as a new fibrotic marker in liver fibrosis and interstitial

lung disease (ILD) to detect unique fibrosis-related glycoalteration.

Objectives: The aim of this study is to evaluate the utility of serum Mac-2 binding protein glycosylation isomer (M2BPGi) levels in patients with rheumatic diseases (RD).

Methods: We retrospectively measured serum M2BPGi levels in 68 patients with $\mathrm{RD}$ and 16 healthy controls $(\mathrm{HC})$. There were no patients of cirrhosis and active hepatitis. Serum levels of M2BPGi were measured using HISCL M2BP glycosylation isomer Assay Kit. We examined the relationship between serum M2BPGi levels and clinical parameters in patients with RD.

Results: In patients with RD, the median age was 62.0 years and $79.4 \%$ of them were female.

Serum M2BPGi levels were significantly higher in patients with RD than in HC (median 0.98 cutoff index [COI], $0.32 \mathrm{COI}$, respectively; $\mathrm{P}<0.00001$ ). Patients with SLE tended to have higher serum M2BPGi levels than other rheumatic diseases.

In patients with $\mathrm{RD}$, a significant correlation was not found between serum M2BP levels and inflammation markers such as CRP or ferritin. However, serum M2BPGi levels were significantly correlated with B cell activation markers such as immunoglobulin free light chain and $\lg G(r=0.588,0.504)$ and T cell activation marker such as sIL-2R $(r=0.408)$.

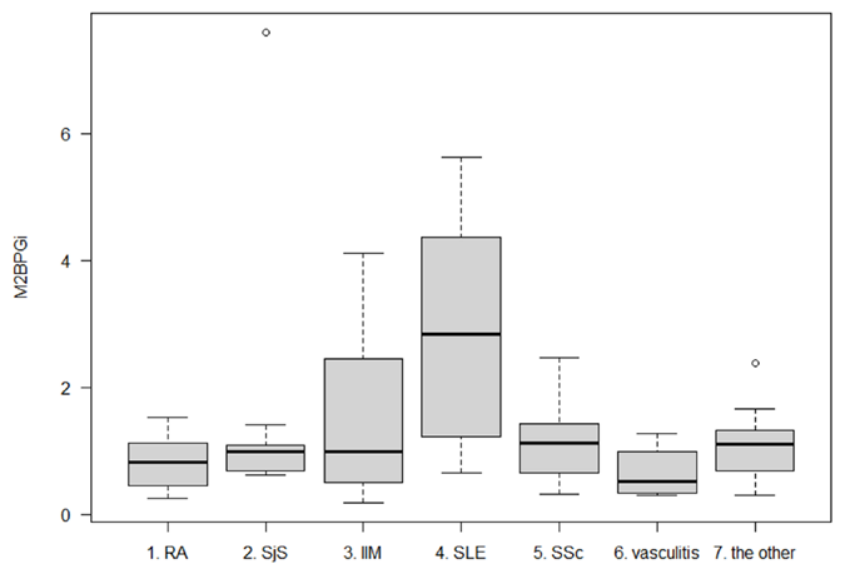

Conclusion: Most of the rheumatic diseases in this study were considered to be type I interferonopathy diseases such as rheumatoid arthritis, Sjogren's syndrome, inflammatory myositis, scleroderma and SLE.

Serum M2BPGi was reported to have a significant correlation with SLE disease activity [SS Ahn et al. Lupus. 2018; 27: 771], and also to have a significant cor relation with Gakectin-9, a novel biomarker for IFN signiture [Lucas L van den Hoogen et al. Ann Rheum Dis. 2018; 77: 1810].

So, it was suggested that serum M2BPGi may be a novel biomarker that indirectly indicates how much IFN is activated in rheumatic diseases.

Disclosure of Interests: None declared

DOI: 10.1136/annrheumdis-2021-eular.1494

\section{AB0312 INCREASED PREVALENCE OF OBSTRUCTIVE SLEEP APNEA IN INDIVIDUALS WITH SYSTEMIC LUPUS ERYTHEMATOSUS}

R. Meidan ${ }^{1,2}$, D. Paran ${ }^{2,3}$, R. Tauman ${ }^{2,4}$, V. Furer ${ }^{2,3}$, T. Eviatar ${ }^{2,3}$,

D. Levartovsky ${ }^{2,3}$, A. Polachek ${ }^{2,3}$, J. Wollman ${ }^{2,3}$, H. Padova ${ }^{2,3}$, M. Zisapel ${ }^{2,3}$, M. Anouk ${ }^{2,3}$, E. Seyman ${ }^{2,5}$, O. Elkayam ${ }^{2,3}$, O. Elalouf ${ }^{2,3}$. ${ }^{1} T e l$ Aviv Sourasky Medical Center, Internal Ward B, Tel Aviv, Israel; ${ }^{2}$ Tel Aviv University, Sackler Faculty of Medicine, Tel Aviv, Israel; ${ }^{3}$ Tel Aviv Sourasky Medical Center, Rheumatology, Tel Aviv, Israel; ${ }^{4}$ Tel Aviv Sourasky Medical center, Sleep Medicine Center, Tel Aviv, Israel; ${ }^{5}$ Tel Aviv Sourasky Medical Center, Neurology, Tel Aviv, Israel

Background: Sleep disturbances are common in individuals with rheumatological diseases in general and systemic lupus erythematosus (SLE) in particular ${ }^{1}$ Studies suggest that obstructive sleep apnea (OSA) might correlate with SLE disease activity and the presence of additional symptoms such as pain, fatigue affective symptoms and steroid $u^{2} e^{2}$. Sleep disturbances symptomatology such as fatigue and increased pain overlap with constitutional inflammatory symptoms of SLE and may mimic or mask disease related relapse ${ }^{3,4}$. Therein lies the importance of diagnosing and treating such disorders in SLE.

Objectives: To determine whether patients with SLE have increased prevalence of OSA as assessed by the apnea hypopnea index (AHI) and to explore possible contributors to OSA including SLE disease activity and accrued damage, medications, secondary fibromyalgia and depression.

Methods: 42 consecutive patients with SLE (38 women, 4 men) and 20 healthy sex, body mass index (BMI) and age matched controls (15 women, 5 men) were consecutively recruited and underwent an ambulatory sleep study using the WatchPAT device. All participants completed questionnaires including Pittsburgh Sleep Quality Index (PSQI), Epworth Sleepiness Scale (ESS), Functional Assessment of Chronic IIIness Therapy (FACIT), Widespread Pain Index (WPI), Symptoms Severity Scale (SSS) and Beck Depression Inventory. SLE disease activity and damage were assessed using the Systemic Lupus Erythematosus Disease Activity Index (SLEDAI) and Systemic Lupus International Collaborating Clinics (SLICC) damage index.

Results: The mean AHI was $9.19 \pm 6.79$ in the SLE group and $3.95 \pm 3.47$ in the control group $(p=0.004)$. Moderate-severe OSA $(A H I \geq 15)$ was significantly more common in patients with SLE $(23.6 \%$ vs. $0 \%, p=0.04)$. Patients with SLE had lower sleep efficiency $(83.38 \pm 6.15$ vs. $87.22 \pm 4.24, p=0.03)$, increased sleep arousals $(7.72 \pm 5.66$ vs. $5.13 \pm 2.29, \mathrm{p}=0.01)$, higher PSQI and FACIT scores SLE $(8.14 \pm 3.47$ vs. $5.10 \pm 2.64, p=0.001,16.89 \pm 11.19$ vs. $7.29 \pm 5.93, p=$ 0.0008 respectively) and had more fibromyalgia as assessed by WPI and SSS

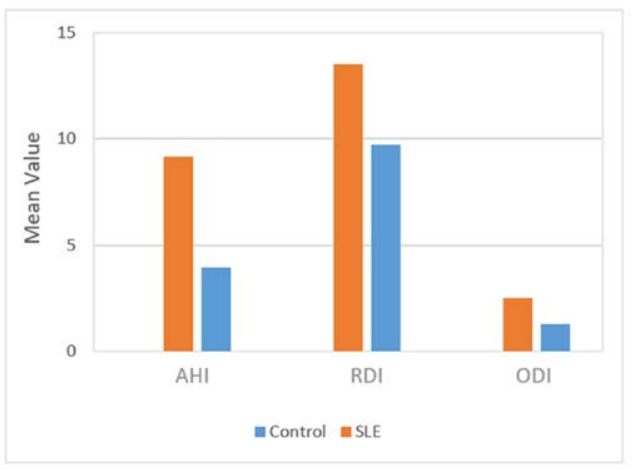

SLE, Systemic Lupus Erythematosus; RDI, Respiratory Disturbance Index; AHI, Apnea Hypopnea Index; ODI, Oxygen Desaturation Index 
(19.5\% vs. $0 \%, p=0.04)$. BMI and the SLICC score were independent predictors of OSA ( $p=0.03$ and $p=0.02$ respectively). A correlation between SLEDAI and moderate-severe OSA was found $(p=0.03)$, although an association to medications, secondary fibromyalgia and depression was not found.

Conclusion: Patients with SLE have increased prevalence of OSA with lower sleep quality compared to healthy controls. Our findings suggest a possible correlation between accrued damage as assessed by the SLE damage index and OSA. REFERENCES:

[1] Wu, L., Shi, P. L., Tao, S. S., Tao, J. H. \& Wu, G. C. Decreased sleep quality in patients with systemic lupus erythematosus: a meta-analysis. Clin. Rheumatol. (2020) doi:10.1007/s10067-020-05300-3.

[2] Palagini, L. et al. Sleep disorders and systemic lupus erythematosus. Lupus vol. 23 115-123 (2014)

[3] Javaheri, S. \& Javaheri, S. Update on Persistent Excessive Daytime Sleepiness in OSA. Chest vol. 158 776-786 (2020)

[4] Mertz, P. et al. Towards a practical management of fatigue in systemic lupus erythematosus. Lupus Science and Medicine vol. 7 (2020).

Table 1. WatchPAT sleep parameters analysis

\begin{tabular}{lccc}
\hline & $\begin{array}{c}\text { SLE group } \\
\mathrm{n}=42\end{array}$ & $\begin{array}{c}\text { Control group } \\
\mathrm{n}=20\end{array}$ & P value \\
\hline $\mathrm{RDI} \pm \mathrm{SD}$ & $13.52 \pm 6.54$ & $9.72 \pm 3.60$ & 0.04 \\
$\mathrm{AHI} \pm \mathrm{SD}$ & $9.19 \pm 6.79$ & $3.95 \pm 3.47$ & 0.004 \\
$\mathrm{ODI} \pm \mathrm{SD}$ & $2.54 \pm 2.72$ & $1.27 \pm 1.45$ & 0.04 \\
Sleep efficiency (\%) $\pm \mathrm{SD}$ & $83.38 \pm 6.15$ & $87.22 \pm 4.24$ & 0.03 \\
Number of arousals \pm SD & $7.72 \pm 5.66$ & $5.13 \pm 2.29$ & 0.01 \\
Saturation $(\%) \pm \mathrm{SD}$ & $96.10 \pm 1.37$ & $95.75 \pm 1.39$ & 0.45 \\
Sleep latency $\pm \mathrm{SD}$ & $21.25 \pm 9.33$ & $18.46 \pm 6.63$ & 0.27 \\
REM latency $\pm \mathrm{SD}$ & $87.88 \pm 49.06$ & $73.60 \pm 46.21$ & 0.09 \\
REM \pm SD & $25.35 \pm 14.03$ & $27.32 \pm 6.79$ & 0.15 \\
Light sleep $\pm \mathrm{SD}$ & $57.63 \pm 12.37$ & $52.70 \pm 11.63$ & 0.18 \\
Deep sleep $\pm \mathrm{SD}$ & $17.89 \pm 5.59$ & $18.76 \pm 6.70$ & 0.54
\end{tabular}

SLE, Systemic Lupus Erythematosus; RDI, Respiratory Disturbance Index; SD, Standard Deviation; AHI, Apnea Hypopnea Index; ODI, Oxygen Desaturation Index; REM Rapid Eye Movement.

Disclosure of Interests: None declared

DOI: 10.1136/annrheumdis-2021-eular.1524

\section{AB0313 WITH IMMUNE-ASSOCIATED ADVERSE PREGNANCY}

W. Su ${ }^{1,2}$, Y. Zhuang ${ }^{1,2}$, J. Zhu',2. 'Sichuan Provincial People's Hospital, University of Electronic Science and Technology of China, Department of Rheumatology and Immunology, Chengdu, China; ${ }^{2}$ Chinese Academy of Sciences Sichuan Translational Medicine Research Hospital, Department of Rheumatology and Immunology, Chengdu, China

Background: Immune-associated adverse pregnancy is the adverse pregnancy outcomes induced by autoimmune factors or autoimmune diseases, including infertility, recurrent spontaneous abortion, failed assisted reproduction, fetal growing restriction. It is helpful to explore the mechanism and improve the management by analyzing the clinical characteristics of patients with immune-associated adverse pregnancy.

Objectives: To find the risk factors of Immune-associated adverse pregnancy by analyzing the clinical characteristics of patients with immune-associated adverse pregnancy.

Methods: The patients involved in this study were from the multi-department clinic of immune-associated adverse pregnancy, during April 2019 and August 2020. They were diagnosed with autoimmune diseases according to relative classification standards or with autoimmune abnormality. Patients with adverse pregnancy due to anatomic, endocrine, infectious and chromosomal factors were excluded.

Results: A total of 107 patients were included. The average age was 29.3 years old. The number of total adverse pregnancy was 115 and the average was 1.07. For the diagnosis, $22(22.4 \%)$ were autoimmune abnormality (with autoantibody but cannot be classified to any autoimmune disease), $30(28.0 \%)$ were antiphospholipid syndrome (APS), 17 (15.9\%) were systemic lupus erythematosus (SLE), $13(12.1 \%)$ were mixed connective tissue disease (MCTD), $8(7.5 \%)$ were undifferentiated connective tissue disease, $5(4.7 \%)$ were Sjogren syndrome (SS), other autoimmune disease account for 10 (9.4\%). For the antibodies, the positive rate of ANA was $44.8 \%$ (48/107), anti-SSA 36.4\% (39/107), anti-RNP $15.0 \%$ (16/107), anti-dsDNA8.4\% (9/107), anti-Sm 9.3\% (10/107), anticardiolipin antibody $17.8 \%$ (19/107), anti-B2GP1 24.3\% (26/107), LA 8.4\% (9/107), non-criteria antiphospholipid antibody $3.7 \%(4 / 107)$.

Conclusion: Our data showed that autoimmune abnormality, SLE, APS, MTCD and SS impacted immune-associated adverse pregnancy the most. The most crucial antibodies were ANA, anti-SSA, anti-RNP, anti-dsDNA and antiphospholipid antibodies.

Disclosure of Interests: None declared

DOI: 10.1136/annrheumdis-2021-eular.1806

\section{AB0314 \\ SEMAPHORIN 3A LEVELS IN LUPUS WITH AND WITHOUT SECONDARY ANTIPHOSPHOLIPID ANTIBODY SYNDROME AND RENAL INVOLVEMENT}

G. S. Kart-Bayram ${ }^{1}$, D. Bayram ${ }^{1}$, A. Erden², S. C. Güven², B. Özdemir², H. Apaydın ${ }^{2}$ A. Omma ${ }^{2}$, Ö. Karakaş ${ }^{2}$, B. Armagan ${ }^{2}$, K. Gok ${ }^{2}$, Y. Maraş ${ }^{2}$, O. Ateş ${ }^{3}$, C. Topçuoğlu ${ }^{3}$, O. Küçükşahin ${ }^{2}$, S. Erten ${ }^{2} .{ }^{1}$ Ankara Şehir Hastanesi, Internal Medicine, Ankara, Turkey; ${ }^{2}$ Ankara Șehir Hastanesi, Rheumatology, Ankara, Turkey; ${ }^{3}$ Ankara Şehir Hastanesi, Biochemical, Ankara, Turkey

Background: In this study, we aimed to evaluate sema3A levels in SLE patients with and without renal involvementor secondary antiphospholipid antibody syndrome (APS), to further elucidate the contribution ofsema3A in etiopathogenesis these conditions

Objectives: Aim of this study is to evaluate sema3A levels in systemic lupus erythematosus patients (SLE) with and without renal involvement and secondary antiphospholipid antibody syndrome (APS).

Methods: SLE patients were grouped according to presence of secondary APS or renal involvement. The control group consisted of age-matched, nonsmoker, healthy volunteers. Sema3A levels were compared among groups. All SLE patients were regrouped according to presence of thrombotic events, miscarriages and proteinuria and sema3 $\mathrm{A}$ levels were investigated. Finally, sema3A levels of all SLE patients as a single group were compared to controls.

Results: The mean sema3A values were $16.16 \pm 2.84 \mathrm{ng} / \mathrm{dL}$ in the control group $11.28 \pm 5.23 \mathrm{ng} / \mathrm{dL}$ in SLE patients without nephritis and APS, $9.05 \pm 5.65 \mathrm{ng} / \mathrm{dL}$ in SLE with APS group, and $8.53 \pm 5.11 \mathrm{ng} / \mathrm{dL}$ in lupus nephritis group. When all three patient groups were examined as a single group, mean sema3A value was significantly lower than that of the control group. Sema3A was reduced in SLE patients with thromboembolism and/or miscarriage.

Conclusion: Sema3A levels were lower in all patient groups compared to the control group. Moreover, the reduced sema3A levels in patients with a history of thromboembolism and/or miscarriage suggests that sema3A may play an important role in the pathogenesis of vasculopathy

Table 1. Comparison of sema3A levels between SLE patient groups and control subjects

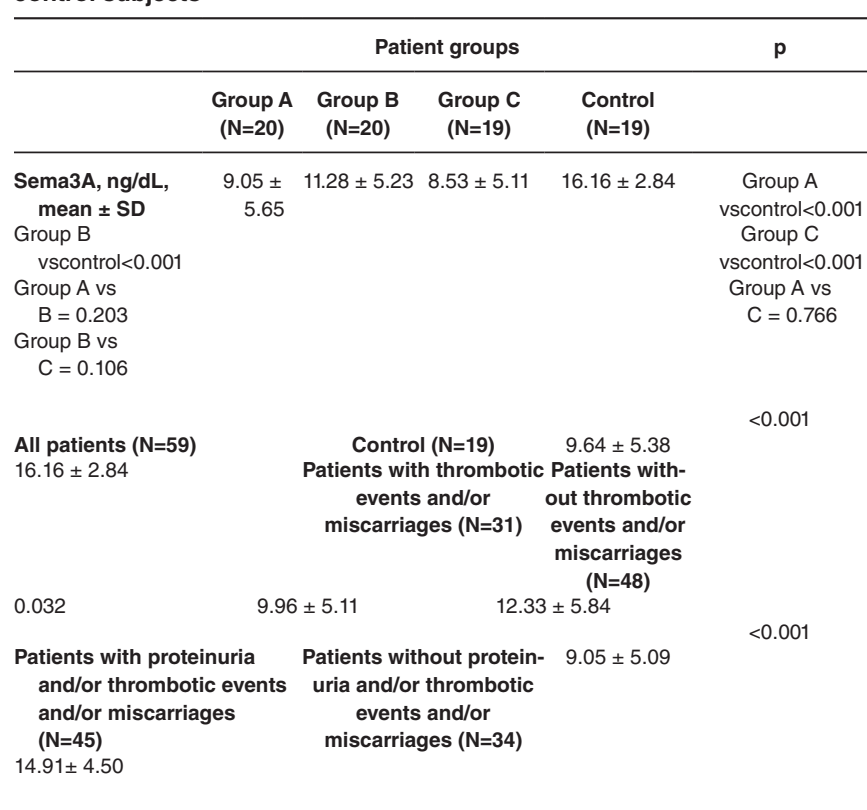

Disclosure of Interests: None declared

DOI: 10.1136/annrheumdis-2021-eular.1864

\begin{tabular}{|l|l}
\hline AB0315 & DISEASE DAMAGE ACCRUAL AND LOW BONE \\
MINERAL DENSITY IN FEMALE PATIENTS WITH \\
SYSTEMIC LUPUS ERYTHEMATOSUS
\end{tabular}

M. Correa Rodríguez ${ }^{1,2}$, G. Pocovi-Gerardino ${ }^{2}$, J. L. Callejas-Rubio ${ }^{2,3}$, R. Ríos Fernández $^{2,3}$, S. Delolmo-Romero ${ }^{1}$, N. Ortego ${ }^{2,4}$, B. Rueda-Medina ${ }^{1,2}$.

${ }^{1}$ University of Granada, Nursing, Granada, Spain; ${ }^{2}$ Biohealth Research Institute 